\title{
Structure-activity mapping of the peptide- and force-dependent landscape of T-cell activation
}

Yinnian Feng ${ }^{1}$, Xiang Zhao ${ }^{2}$, Adam K. White ${ }^{1}$, K. Christopher Garcia ${ }^{2,3,4}$ and Polly M. Fordyce ${ }^{1,5,6,7,{ }^{*}}$

${ }^{1}$ Department of Genetics, Stanford University, Stanford, CA, USA

${ }^{2}$ Department of Molecular and Cellular Physiology, Stanford University, Stanford, CA, USA

${ }^{3}$ Department of Structural Biology, Stanford University, Stanford, CA, USA

${ }^{4}$ Howard Hughes Medical Institute, Chevy Chase, MD, USA

${ }^{5}$ Department of Bioengineering, Stanford University, Stanford, CA, USA

${ }^{6}$ ChEM-H Institute, Stanford University, Stanford, CA, USA

${ }^{7}$ Chan Zuckerberg BioHub, San Francisco, CA USA

${ }^{\star}$ Correspondence: pfordyce@stanford.edu

\section{SUMMARY}

Adaptive immunity relies on T lymphocytes that use $\alpha \beta$ T-cell receptors (TCRs) to discriminate amongst peptides presented by MHC molecules (pMHCs). An enhanced ability to screen for pMHCs capable of inducing robust T-cell responses could have broad applications in diagnosing and treating immune diseases. T cell activation relies on biomechanical forces to initiate triggering of the TCR. Yet, most in vitro screening technologies for antigenic peptides test potential pMHCs for T cell binding without force and thus are often not predictive of activating peptides. Here, we present a technology that uses biomechanical force to initiate T cell triggering in high throughput. BATTLES (Biomechanically-Assisted I-cell Triggering for Large-scale Exogenous-pMHC Screening) displays candidate pMHCs on spectrally encoded 'smart beads' capable of applying physiological loads to T cells, facilitating exploration of the forceand sequence-dependent landscape of T-cell responses. BATTLES can be used to explore basic T-cell mechanobiology and T cell-based immunotherapies.

\section{KEYWORDS: T-cell receptor, T-cell activation, spectrally encoded beads, high-throughput mechanobiology, ligand discrimination, catch bond, T-cell biophysics, single-cell microfluidics, mechanotransduction.}

\section{INTRODUCTION}

The adaptive immune response relies on the ability of $T$ cells to sensitively discriminate non-self from self, allowing mammals to detect pathogen infection or malignant transformations. At a molecular level, this process is mediated by $\alpha \beta T$ cell receptors (TCRs) that recognize specific peptides presented by major histocompatibility complex (MHC) molecules expressed on antigen presenting cells (APCs). T cell recognition of a pMHC molecule via its TCR triggers downstream signaling events $\left(e . g . \mathrm{Ca}^{2+}\right.$ flux) that ultimately regulate the activation state of the $\mathrm{T}$ cells. The parameters that determine whether a given $\mathrm{pMHC}$ antigen will bind and trigger $\mathrm{T}$ cell activation have been extensively studied, but important questions remain about the inter-relationship between binding and TCR triggering. An enhanced understanding of these molecular mechanisms, as well as peptide screening methods that simultaneously probe both of these parameters, would have broad applications for immune and infectious disease diagnosis and treatment.

Currently, it is not possible to predict which peptide sequences will engage and activate a particular TCR. In vivo, T cell detection of antigenic peptides is exquisitely sensitive, capable of identifying <10 nonself/altered peptides (Huang et al., 2013; Purbhoo et al., 2004) on infected or transformed cells (Keskin et al., 2015). This detection is also highly specific, effectively distinguishing peptides that differ by only a single amino acid (Sasada et al., 2000). By contrast, measured in vitro 3D affinities for known stimulatory peptides are surprisingly weak $\left(K_{d} \sim \mu \mathrm{M}\right)$ and often do not differ significantly from non-stimulatory peptides ( $\mathrm{K}_{\mathrm{d} \text {, non-self }}<10 \mathrm{~K}_{\mathrm{d} \text {, self }}$ ) (Huang et al., 2010). In addition, measured in vitro affinities often do not accurately correlate with T-cell activity (Huang et al., 2010; Lyons et al., 1996; Stone et al., 2009). Many high-affinity interactions occur with high frequency in the human $\mathrm{T}$ cell repertoire yet do not stimulate a $T$ cell response (Sibener et al., 2018), while many of the most potent stimulatory peptides bind with only 
weak or moderate affinities (Corse et al., 2010; Ueno et al., 2004). Together, these paradoxical results establish that equilibrium binding is not sufficient to explain T cell recognition in vivo.

Recent evidence suggests that the $\mathrm{pN}$ to $\mathrm{nN}$ biomechanical forces generated at TCR-pMHC interfaces during T-cell immunosurveillance and synapse formation may be critical for sensitive and specific recognition (Feng et al., 2018). For stimulatory peptides, single TCR-pMHC complex bond lifetimes increase with loads up to an optimal force (characteristic for 'catch bonds'); for non-stimulatory peptides, bond lifetimes shorten as force increases (characteristic for 'slip bonds') (Das et al., 2015; Liu et al., 2014; Sibener et al., 2018). Distinguishing agonist peptides ('catch') from non-agonist peptides ('slip') requires an in vitro assay in the presence of applied loads that quantifies not just binding but downstream activation.

A variety of in vitro assays have been designed to identify peptides with potent stimulatory potential. Affinity-based screening approaches (e.g. DNA-barcoded pMHC multimer screening (Bentzen et al., 2016; Bentzen et al., 2018; Zhang et al., 2018) and pMHC yeast display (Birnbaum et al., 2014)) assay $10^{3}-10^{9}$ different sequences, facilitating deep exploration of the vast potential sequence space. However, these assays quantify binding alone (and not activation), take place in the absence of force, and present peptides at artificially high local concentrations, reducing their physiological relevance. Synthetic biology approaches that co-culture engineered T cell lines with peptide-pulsed APCs directly assess cellular responses (Joglekar et al., 2019; Kula et al., 2019; Li et al., 2019), yet peptides remain displayed at artificially high densities. By contrast, low-throughput mechanobiology techniques (e.g. traction force microscopy (Bashour et al., 2014; Basu et al., 2016; Dustin and Groves, 2012; Hui et al., 2015; Liu et al., 2016a), optical trapping (Feng et al., 2017; Wei et al., 1999), atomic force microscopy (Hu and Butte, 2016), biomembrane force probes (Husson et al., 2011; Li et al., 2010; Liu et al., 2014), and optomechanical actuator nanoparticles (Liu et al., 2016b)) can exert external well-calibrated shear loads on $\mathrm{T}$ cells interacting with specific pMHCs displayed at low densities. However, these techniques typically require extensive costly equipment and are labor intensive, restricting measurements to one or a limited number of peptide sequences.

Here, we present a novel technology (BATTLES, for Biomechanically-Asssisted I-cell Iriggering for Large-scale Exogenous-pMHC Screening) that profiles T cell signaling responses for thousands of cells interacting with different pMHCs at low densities and in the presence of physiological shear loads in a single experiment. To test and validate the BATTLES technology, we profiled responses of two T cell lines (TCR589 and TCR55) previously shown to bind an HIV pol-derived peptide (IPLTEEAEL, HIVpol). BATTLES measurements for >11,000 TCR589 and TCR55 cells interacting with 21 peptides (Sibener et al., 2018) correctly recapitulated known responses for TCR589 and identified an alternate synthetic peptide sequence (VPLTEDALL) capable of stimulating TCR55 cells with as few as three TCR-pMHC interactions at the interface. By using BATTLES to systematically vary the magnitude of the applied force and the density of presented peptides, we further establish that TCR55 cells interacting with this alternate synthetic peptide exhibit catch bond-like behavior with the strongest response at 20-30 pN/s loads, and that observed specificities decrease with increasing pMHC densities. Finally, we apply BATTLES to profile responses of a third clinically relevant TCR (DMF5) previously shown to interact with two different peptide classes (Riley et al., 2018). These model systems establish BATTLES as a new technology suitable for obtaining deeper insight into the structure-activity relationships of TCR triggering and discovering novel pMHC antigens under conditions of physiological force.

\section{RESULTS}

To apply well-calibrated shear forces, BATTLES deposits T cells onto the surface of hydrogel 'smart beads' bearing pMHCs that swell upon small changes in temperature (Figure 1A). To monitor downstream signaling responses via high-throughput single-cell microscopy, T cells and 'smart beads' are loaded into microwell arrays in the presence of a $\mathrm{Ca}^{2+}$-sensitive dye (Figure 1B). By linking pMHCs to spectrally encoded 'smart beads' with a 1:1 relationship between the presented peptide sequence and embedded spectral code, each BATTLES experiment can profile responses of $\sim 1000-3000$ cells interacting with $>20$ peptide sequences. 


\section{'Smart' beads can apply well-calibrated loads to single cells}

Stimulus-responsive polymers have been widely used to probe mechanobiology within bulk tissues and for single cells (Kim and Hayward, 2012), including T cells (Liu et al., 2016b). However, the forces applied by these 'smart' materials have been difficult to quantify due to heterogeneity over large distances (Chandorkar et al., 2019). Moreover, while T cell crawling takes place over second-to-minute timescales and $\mu \mathrm{m}$-scale distances, these materials typically apply near-instantaneous forces (within ms) at nm-scale (Liu et al., 2016b).

'Smart beads' that shrink and swell can apply homogeneous expansion forces (Ding et al., 2016; Lau et al., 2002) (Figure 1C), with the shear load applied at bead surfaces given by Eqn. 1:

$$
F=\frac{2 R_{\text {cell }}}{\sqrt{6}} \times \frac{\kappa}{\sqrt{R_{\text {bead }}}} \times \Delta R_{\text {bead }}{ }^{1.5} \quad \text { Eqn. } 1
$$

where $R_{\text {cell }}$ is the T cell radius ( $4 \mu \mathrm{m}$ for the SKW3 cell line used here), $\mathrm{k}$ is the modulus of rigidity, $R_{\text {bead }}$ is the starting bead radius, and $\Delta R_{\text {bead }}$ is the radius change of the bead. 'Smart beads' can be generated from temperature-responsive polymers such as poly(N-isopropylacrylamide) (PNIPAm), which changes size at a critical temperature (Figure 1D) that can be tuned to a physiological range (e.g. $34-35^{\circ} \mathrm{C}$ ) by adding hydrophilic comonomers (e.g. acrylic acid (AAc) or sodium acrylate (SAc)) (Burmistrova et al., 2011). Here, we generated monodisperse 'smart beads' (radius $=16.10 \pm 0.4 \mu \mathrm{m}$, mean $\pm \mathrm{SD}$ ) by using a single-layer microfluidic droplet generator (Feng et al., 2020) (Figure S1A; Movie S1) to produce NIPAm droplets containing $55 \mathrm{mM}$ SAc (Figure S1B) and then polymerized these droplets into solid beads via batch exposure to UV light. After polymerization and swelling in aqueous buffer, this process yielded $\sim 23.75 \mu \mathrm{m}$ radius beads $(\mathrm{CV}=6.5 \%)$ at room temperature (Figure S1C).

To quantify changes in radii as a function of temperature, we loaded 12 beads onto an indium tin oxide (ITO) glass slide and imaged while raising the temperature to $37^{\circ} \mathrm{C}$ for $60 \mathrm{~s}$ and then allowing the temperature to ramp down to $34^{\circ} \mathrm{C}$ over $120 \mathrm{~s}$ (Figure 1E; Movie S2). 'Smart bead' radii shrank by $1.49 \pm$ $0.16 \mu \mathrm{m}$ during the first $30 \mathrm{~s}$ after heating and then expanded by $0.81 \pm 0.06 \mu \mathrm{m}$ after cooling (Figures 1F and 1G). After $60 \mathrm{~s}$, the thermo-response reached equilibrium and the bead radius remained constant. $\mathrm{A} 37^{\circ} \mathrm{C}$ to $34^{\circ} \mathrm{C}$ temperature change has only minimal effects on early immune cell activation (Hanson, 1993; WoldeMussie et al., 1986), suggesting signaling responses should reflect the response to force alone.

Next, we measured the modulus of rigidity $(\mathrm{K})$ for a hydrogel slab comprised of identical concentrations of NIPAm monomer and SAc (Figure S2A). The measured modulus was $\sim 3 \mathrm{kPa}$ (Figure S2B), similar to rigidities for epithelial cells that support CD8+ cytotoxic T cell crawling $(4.6 \pm 2.2 \mathrm{kPa})(\mathrm{Wu}$ et al., 2018) and lymph nodes ( $\sim \mathrm{kPa}$ ) (Meng et al., 2020). Combining measured radii, changes in radii, and moduli yields estimated ramping forces of $20 \pm 2 \mathrm{pN} / \mathrm{s}$ (Figure 1H), in good agreement with physiological forces applied by T cells (estimated to be $21.5 \mathrm{pN} / \mathrm{s}$ (Hui et al., 2015) with forces applied over minutes (Huse, 2017)).

\section{Spectrally encoded 'smart' beads allow simultaneous testing of many potential antigenic sequences}

Developing a quantitative and predictive biophysical understanding of how peptide sequence dictates $T$ cell signaling requires the ability to systematically vary presented sequences while assessing downstream responses. We previously demonstrated that poly(ethylene glycol) diacrylate (PEG-DA) hydrogel beads can be spectrally encoded via the incorporation of different ratios of lanthanide nanophosphors (Lns) (Figure 2A) and that bead surfaces can be functionalized for downstream chemical coupling (MRBLEs, for Microspheres with Ratiometric Barcode Lanthanide Encoding) (Feng et al., 2020; Gerver et al., 2012; Nguyen et al., 2017).

To test if thermally-responsive PNIPAm is compatible with spectral encoding, we generated carboxylated PNIPAm beads containing a constant amount of Europium (Eu) and varying amounts of Dysprosium (Dy), and Samarium (Sm) (Figure 2B; Table S1), pooled all codes prior to imaging, and analyzed images using previously developed software (Harink et al., 2019). Per-bead Sm/Eu and Dy/Eu ratios revealed 21 distinct clusters consistent with expected target ratios (Figure 2C). Cluster variances were similar to those for PEG-DA beads (Gerver et al., 2012) (Figure S3A), with a coding capacity of 35, 48, 80, or 143 codes for clusters separated by 6, 5, 4, or 3 standard deviations, respectively (Figures S3B and S3C).

\section{'Smart' beads can display peptides at low physiological densities to mimic in vivo conditions}


Applying shear forces to bead-interacting $T$ cells under physiological conditions requires that pMHC complexes be conjugated to beads at low densities. To accomplish this, we covalently coupled streptavidin (SA) proteins to carboxyl groups via EDC chemistry. After SA coupling, codes remained easily distinguishable from one another (Figure S4A); incubation of SA-coated and uncoated beads with ATTO-647-labeled biotin further established that SA coupling was uniform and specific (Figures S4B-S4D).

We then synthesized a library of peptides containing systematic mutations within an HIVpol-derived peptide (Pol448-456, IPLTEEAEL) that was previously used to test the effects of amino acid substitutions at positions P1 and P3-9 on T cell binding via yeast display (Figure 2D). These 21 peptides had previously measured $\mathrm{EC}_{50}$ values from $1.2 \mu \mathrm{M}$ to $>100 \mu \mathrm{M}$ and contain systematic substitutions at TCR-contacting (P1, P4, P5, and P8) and neutral residues (P3, P6 and P7) (Figure 2E; Table S2).

To display peptides on 'smart beads', we loaded peptides of interest in the B35 MHC groove of biotinylated pMHC complexes via UV-facilitated peptide exchange in solution (Rodenko et al., 2006) and then incubated biotinylated pMHC complexes with SA-coated beads (Figure 2F). All UV exchanges and bead coupling reactions took place in separate volumes to uniquely link peptide sequences with embedded spectral codes. To quantify the actual density of interfacial pMHC molecules, we incubated beads bearing pMHC complexes with fluorescently-labeled anti- $\beta 2$ monoclonal antibodies (which recognize the $\beta 2$ microglobulin within pMHCs successfully loaded with peptides) and imaged bead surfaces via total internal reflection fluorescence (TIRF) microscopy (Figure 2G). As hydrogel beads are compliant, beads settled on coverslip surfaces to yield an observable spot $~ 50 \mu \mathrm{m}$ in diameter (Figure $\mathbf{2 H}$ ), with individual antibody-labeled interfacial pMHCs appearing as scattered fluorescent punctae. Over 10 beads (from spectral code 8 ), we observed $29 \pm 9$ pMHCs per $\sim 840 \mu^{2}$ of selected bead surface area, corresponding to an expected maximum of 3-4 pMHCs per $100 \mu^{2}$ T cell surface (Figure S5A) $\left(2 \pi r^{2}\right.$, assuming a $\mathrm{T}$ cell $(r=4 \mu \mathrm{m})$ spreading when interacting with a surface and then retracting (Fritzsche et al., 2017)), with significantly fewer pMHCs for negative control beads $(4.4 \pm 1.8$ per selected bead surface area) (Figure S5B). Interfacial densities were uniform across codes ( 0.03 to 0.045 molecules $/ \mu^{2}$, corresponding to 3-4.5 molecules/T cell) (Figure 2l).

Attributing differences in measured activation to changes in sequence requires that applied force be constant across codes. For all 21 codes, mean bead radii and changes in radii upon cooling ranged from 23.0 to $24.6 \mu \mathrm{m}$ and $0.78-0.9 \mu \mathrm{m}$, respectively (Figures S6 and S7); hydrogel rigidity across different Ln ratios also remained fairly constant ( $\mathrm{K}=2.48-3.15 \mathrm{kPa}$ ) (Figure S8). Together, these measurements yield estimated force ramping rates of $20-27.5 \mathrm{pN} / \mathrm{s}$ over $\sim 60$ s (Figure S9), differing by $<27 \%$ across codes.

\section{Pairing $\mathrm{T}$ cells with 'smart' beads for high-throughput monitoring of force- and sequence-dependent activation}

Early T cell activation is associated with elevations in intracellular free calcium (Freedman, 1979), making it possible to monitor TCR responses towards a given peptide using a calcium-sensitive dye (Brazin et al., 2018; Feng et al., 2017; Hu and Butte, 2016; Husson et al., 2011; Kim et al., 2009; Li et al., 2010; Liu et al., 2014; Liu et al., 2016a; Liu et al., 2016b; Ma et al., 2008). To allow high-throughput imaging of many individual T cells in parallel upon the application of shear force to pMHC-TCR interactions, we fabricated a device containing 1440 microwells, each $\sim 50 \mu \mathrm{m}$ in diameter and $\sim 56 \mu \mathrm{m}$ in depth, that allowed sequential loading of a single 'smart bead' within each well followed by 1 or multiple T cells on top (Figures 3A and 3B; Movie S3). After an initial incubation to allow cells to interact with and attach to bead-bound pMHCs, we increased the device temperature to $37^{\circ} \mathrm{C}$ for $1 \mathrm{~min}$ followed by cooling to $34^{\circ} \mathrm{C}$ for 2 mins; subsequent imaging of $\mathrm{Ca}^{2+}$ flux via Cal-520 fluorescence for bead-associated cells over $10 \mathrm{~min}$ ( $4 \mathrm{~s}$ intervals) allowed direct monitoring of single $\mathrm{T}$ cell signaling. After each experiment, we imaged beads across lanthanide channels to identify the embedded spectral code and thus the displayed peptide sequence (Figure S10).

\section{BATTLES correctly identifies peptide agonists known to drive cytotoxic killing in vivo}

To demonstrate BATTLES, we profiled two HLA-B35-HIV(Pol ${ }_{448-456}$ ) (HIVpol)-specific TCRs (TCR589 and TCR55) previously shown to bind HIVpol pMHCs at $\mu \mathrm{M}$ affinities $\left(\mathrm{K}_{\mathrm{D}}=4 \mu \mathrm{M}\right.$ and $17 \mu \mathrm{M}$, respectively) but with divergent downstream responses (Sibener et al., 2018). While TCR589-transduced SKW-3 T lymphoblastic leukemia cells bound HIV-pol tetramers and secreted IL-2 in a dose-dependent manner, the same cell line 
transduced with TCR55 showed $\sim 4 \mathrm{x}$ weaker binding to HIVpol but failed to secrete detectable IL-2. If BATTLES can reliably identify stimulatory peptides, we would therefore expect to see $\mathrm{HIVpol-induced} \mathrm{Ca}^{2+}$ flux for TCR589.

To test this, we quantified $\mathrm{Ca}^{2+}$ flux for TCR589-transduced T cells interacting with all $21 \mathrm{HIVpol-derived} \mathrm{bead-}$ bound pMHCs (Figure 2C; Table S2). Brightfield images demonstrated loading of 'smart beads' within all microwells (Figure 3B), and movies acquired during device heating and cooling established that cooling swelled beads as expected and that $\mathrm{T}$ cells remained in contact with bead surfaces throughout (Figure 3B; Movie S4). After cooling, fluorescence images of force-induced $\mathrm{Ca}^{2+}$ flux for 961 cells across all peptides (66 \pm 18 beads and $46 \pm 15$ cells per peptide, Figure S11) revealed a variety of behaviors (Figures 3C-3E). While some $T$ cells exhibited substantial and rapid increases in intracellular calcium (typical of a type- $\alpha$ calcium response indicating successful TCR triggering) (Figure 3D, top), most cells showed decreasing fluorescence intensities over time, reflecting an absence of triggering (type- $\beta$ calcium response) combined with photobleaching (Figure 3D, bottom; Figure S12A). This is consistent with prior literature suggesting that only a fraction of cells are activated at low pMHC densities, even under optimal force (Ma et al., 2008).

To probe for sequence-dependent differences in the proportion of triggered cells and amplitude of type- a calcium responses, we integrated per-cell fluorescence over time and then analyzed only 'positive' cells that increased in fluorescence (Eqn. 2):

$$
\int\left(\frac{I}{I_{0}}-1\right)>0
$$

For TCR589 cells, the HIVpol peptide (IPLTEEAEL) yielded the highest percentage of 'positive' $T$ cell responses (Figure S12B; Movie S5) and 'positive' cells had larger integrated intensity signals ( 2-fold greater than for other peptides (Figures 3E-3G, S13; $p=10^{-4}$ as determined via bootstrapping analysis against all other peptide sequences, see Methods). Results were consistent across technical replicates (Figures $3 H$, S14 and $\mathbf{S 1 5} ; r^{2}=0.41$ ), establishing that BATTLES can identify peptide epitopes capable of producing a robust cytotoxic response in vivo.

\section{Applying BATTLES to identify novel peptide agonists}

Next, we tested whether BATTLES could identify novel likely potent agonists for TCR55-tranduced T cells that bind HIVpol without activation (Figures 4A and S16; $67 \pm 24$ beads and $51 \pm 23$ cells per peptide). In contrast with TCR589, the HIVpol peptide IPLTEEAEL did not induce significant $\mathrm{Ca}^{2+}$ responses; instead, a mutant version of this peptide (VPLTEDALL) produced the strongest functional response across 2 full biological replicates in which we shuffled the identity of the peptide associated with each spectral code (Figures 4B-4D, S17-S19; bootstrapped $p=10^{-5}$ and $8 \times 10^{-4}$ for each replicate; $r^{2}=0.62$ between replicates).

To confirm that observed $\mathrm{Ca}^{2+}$ responses required force and were not simply due to changing temperatures, we repeated the TCR55 BATTLES assay after either heating beads to $34^{\circ} \mathrm{C}$ without first heating to $37^{\circ} \mathrm{C}$ or heating to $37^{\circ} \mathrm{C}$ without subsequently reducing temperatures to $34{ }^{\circ} \mathrm{C}$ (Figures S20A and S20B). In both cases, integrated $\mathrm{Ca}^{2+}$ signals across tested peptides were 2-fold lower and a lower percentage of cells yielded positive integrated $\mathrm{Ca}^{2+}$ signals (Figure S20C); in addition, no peptide produced a response significantly higher than the others. Although some shrinking force may be applied during heating to $37^{\circ} \mathrm{C}$, the directions of the applied force and cell contractions ( $6 \mathrm{nN}$ after attachment (Hui et al., 2015)) are aligned at interaction surfaces such that the net applied force is negligible.

\section{Multiplexing applied loads can elucidate 'catch' vs 'slip' bond behavior in a single experiment}

For 'catch' bonds (found in TCR-agonist pMHC interactions), bond lifetimes increase with applied force up to an optimal load (typically 8-20 pN) and then decrease; for 'slip' bonds (found in TCR-self pMHC interactions), bond lifetimes monotonically decrease with applied load (Das et al., 2015; Liu et al., 2014; Sibener et al., 2018) (Figure 5A). If the VPLTEDALL peptide serves as a true potent agonist for TCR55transduced T cells, we would expect to see the strongest triggering at an optimal force, with weaker responses at higher or lower forces. To test this, we leveraged spectrally encoded 'smart beads' to simultaneously vary both the peptide sequences presented and forces applied to pMHC-TCR interactions within a single experiment. 
Incorporating different amounts of SAc within the 'smart bead' matrix alters the relative hydrophilicity/hydrophobicity ratio and thus the change in radius upon temperature-induced swelling and shrinking, tuning the magnitude of the applied force (Figure 5B). To apply a range of forces, we polymerized 'smart beads' containing $50 \mathrm{mM}, 55 \mathrm{mM}$, or $60 \mathrm{mM} \mathrm{SAc}$, respectively (Figure 5B). After polymerization, the radius of polymerized beads was fairly constant for all 3 formulations $(24.12+/-1.45 \mu \mathrm{m}, 23.68+/-1.55 \mu \mathrm{m}$, and $24.08+/-1.66 \mu \mathrm{m}$, mean $\pm \mathrm{SD}$ ) but the magnitude of the change in radius upon cooling from $37^{\circ} \mathrm{C}$ to $34^{\circ} \mathrm{C}$ varied substantially ( $1.44 \mu \mathrm{m}$ ( 34 beads, $\mathrm{CV}=1.5 \%), 0.96 \mu \mathrm{m}$ ( 24 beads, $\mathrm{CV}=5.4 \%$ ), and $0.64 \mu \mathrm{m}$ ( 23 beads, $\mathrm{CV}=2.5 \%)$ ) (Figures 5B, 5C and S21; Movie S6). As the modulus of rigidity is unchanged by small changes in SAc concentration (Burmistrova et al., 2011), these variations yielded ramping forces of $54.43 \pm 1.52 \mathrm{pN} / \mathrm{s}$, $26.96 \pm 2.37 \mathrm{pN} / \mathrm{s}$, and $15.57 \pm 0.62 \mathrm{pN} / \mathrm{s}$ for the 3 formulations (Figures 5D and S22).

Prior work using a BFP-based bond lifetime assay established that for TCR55, VPLTEDAEL and VPITEDSQL peptides exhibit maximum lifetimes at $14 \mathrm{pN}$ and $7 \mathrm{pN}$, respectively, indicating the formation of a 'catch' bond, while the HIVpol peptide (IPLTEEAEL) shows 'slip' bond behavior (Sibener et al., 2018) (Figure S23). Here, we profiled the force-dependent responses for these 3 peptides and the VPLTEDALL peptide shown to drive the largest integrated $\mathrm{Ca}^{2+}$ signal in BATTLES (Figures 4B-4D) via a BATTLES assay in which each spectral code corresponded to a particular sequence/force combination (4 peptide sequences $\times 3$ forces/sequence $=12$ unique codes; $116 \pm 50$ beads and $127 \pm 54$ cells per peptide) (Figures S24; Table S4). Integrated $\mathrm{Ca}^{2+}$ signals as a function of applied load for VPLTEDALL revealed a marked increase in $\mathrm{Ca}^{2+}$ flux at low and moderate forces followed by a decrease in $\mathrm{Ca}^{2+}$ at high force, consistent with 'catch' bond formation (Figure 5E). VPITEDSQL triggered the strongest response at low force, consistent with its previously measured catch bond profile, and VPLTEDAEL responses were uniformly low across all forces. Although HIVpol (IPLTEEAEL) exhibited a slight increase in signal as force increased (Figure $5 E$ ), there was no significant difference between tested forces compared to no force ( $p=0.06$ via bootstrapping). Results were again consistent across an additional full technical replicate in which embedded codes and peptide sequences were shuffled (Table S4; Figures S25 and S26; $r^{2}=0.80$ across replicates).

\section{Multiplexing PMHC sequences and concentrations to reveal dose-dependent immunogenicity}

These BATTLES results suggest that the VPLTEDALL peptide triggers the strongest $\mathrm{Ca}^{2+}$ signaling response for TCR55-transduced T cells, at odds with prior co-culture results identifying VPLTEDAEL as the most potent agonist (Sibener et al., 2018) (Table S3). One potential explanation for this discrepancy could be the difference in presented pMHC concentrations: peptide-pulsed APCs present peptides at densities > $100 \mathrm{nM}$ (corresponding to $\sim 10-30 \mathrm{pMHCs} / \mathrm{T}$ cell at $100 \mathrm{nM}$ (Zehn et al., 2006) and $\sim 313 \mathrm{pMHCs} / \mathrm{T}$ cell at $10 \mu \mathrm{M}$ (Henrickson et al., 2008)) while BATTLES 'smart beads' present pMHCs at physiological densities of 3-4.5 $\mathrm{pMHCs}$ /cell. To test if signaling responses depend on presented densities, we repeated BATTLES assays with the same 4 TCR55-binding peptide sequences (VPLTEDALL, VPITEDSQL, VPLTEDAEL, and IPLTEEAEL) at 3 effective concentrations ( $1 \mathrm{X}$ (3-4.5 pMHCs/T cell); $7 \mathrm{X}$ (21-31.5 pMHCs/T cell); and 27X (81-121.5 pMHCs/T cell)) ( 4 sequences $\times 3$ concentrations $=12$ codes; $116 \pm 36$ beads and $211 \pm 66$ cells per peptide) (Figures 5F, S27 and S28; Table S5). At $1 X$ concentrations, VPLTEDALL again drove the strongest downstream response (Figures 5G-5I, S29 and S30; bootstrapped $p=0.0075 ; r^{2}=0.64$ between replicates). For 7 -fold higher $p M H C$ densities, the integrated $\mathrm{Ca}^{2+}$ signal for VPLTEDALL remained constant but the signals associated with the other 3 peptides increased and showed no significant difference across peptides, indicating a loss of specificity (Figures 5G-5I, S29 and S30A-S30C). At 27-fold higher pMHC densities, the integrated $\mathrm{Ca}^{2+}$ signal associated with the VPLTEDAEL increased even further to drive the strongest response (Figures 5G-5I, S29 and S30AS30C; bootstrapped $p=0.012$ for two replicates), consistent with prior observations from tetramer screening and co-culture assays (Sibener et al., 2018). These results confirm that downstream signaling responses depend on presented density and underscore the importance of screening at physiological pMHC densities for accurate identification of likely potent agonists in vivo.

\section{Understanding the activation potential of TCRs capable of binding multiple distinct peptide classes}

Next, we tested a third TCR with a known potential therapeutic role. The DMF5 TCR recognizes the MART-1 melanoma antigen presented by the class I MHC protein HLA-A*0201 and has been used in clinical trials of engineered $T$ cells interacting with MART-126-35 peptide-loaded dendritic cells that demonstrated robust tumor regression (Chodon et al., 2014). However, prior yeast display experiments 
revealed two distinct classes of peptides that bound the DMF5 TCR: (1) MART-1-like peptides containing a hydrophobic core sequence (GIG in P4-6) and (2) peptides instead containing a highly charged central core (DRG in P4-6), ), with DRG class peptides binding in a unique 'shifted register' conformation (Riley et al., 2018). Tetramers of the MART-1 anchor-modified dodecamer (ELAGIGILTV) showed the strongest binding and the strongest downstream response in peptide-pulsed co-culture assays while IMEDVGWLNV was the most potent DRG class peptide (Figure 6A; Table S6). Predicting whether similar cross-reactivity is likely in therapeutic applications requires the ability to assess activation responses when presented at low densities.

To assess reactivities under physiological densities, we applied BATTLES to DMF5 T cells interacting with 11 peptides: 5 GIG class peptides (including the MART-1 anchor-modified dodecamer), 5 DRG class peptides, and a negative control peptide (Tax, LLFGYPVYV) (124 \pm 34 beads and $75 \pm 29$ cells per peptide) (Figure S31). Consistent with its known biological role, the MART-1 anchor-modified dodecamer (ELAGIGILTV) drove by far the strongest $\mathrm{Ca}^{2+}$ response in DMF5 T cells across two replicates (Figures 6B-6D, S32, S33 and S34; $p=10^{-7}$ and $3 \times 10^{-4}$ from bootstrapping comparisons with Tax; $r^{2}=0.97$ ). From the DRG class, the MMWDRGLGMM (and not the previously identified IMEDVGWLNV) induced the strongest $\mathrm{Ca}^{2+}$ flux $\left(\mathrm{p}=10^{-6}\right.$ and $\mathrm{p}=6.5 \times 10^{-3}$ from bootstrapping comparisons with Tax). Thus, the BATTLES assay can reveal potential cross-reactivity of therapeutical TCRs towards different epitopes, even for motifs sharing no significant similarities, providing clinically relevant information predicting off-target effects.

\section{DISCUSSION}

T cells exert shear forces during immunosurveillance (Huse, 2017) and immune synapse formation on an APC (Grakoui et al., 1999; Wülfing and Davis, 1998). Such physical loads placed on the TCR-pMHC bond can enhance sensitivity and specificity of recognition by facilitating discrimination between 'catch' and 'slip' bondforming complexes. Recapitulating efficient T cell activation in vitro therefore requires the ability to: (1) display a peptide capable of forming a catch bond with a given TCR, (2) apply optimal forces to drive mechanotransduction, and (3) display pMHCs at sufficiently low densities that applied forces are transmitted to individual intramolecular interactions at the $\mathrm{pMHC/TCR}$ interface. While a wide variety of mechanobiology tools have been developed to identify potent peptide agonists (Lei et al., 2020) (as summarized in Table S7), the BATTLES platform is the first (to our knowledge) that recapitulates these physicochemical cues (e.g. active force and low monomeric pMHC density) and screens many peptide sequences for their potential to not just bind TCRs but also activate downstream signaling responses.

Accurately mimicking physiological conditions requires matching not just the magnitude of applied forces but also the ramp rate and overall duration over which forces are applied. In vivo, actin rearrangement is initiated during the first minute of T cell-APC interaction (Ritter et al., 2015), during which cytoskeleton-associated TCRs rapidly form and break bonds with agonist pMHCs. While the estimated force ramp applied by BATTLES 'smart beads' (20-30 pN/s, 1 min duration) is similar to that applied during traction force microscopy (13-30 pN/s) (Hui et al., 2015), optical trapping (30 pN/s (Feng et al., 2017)), and atomic force microscopy (25 pN/s (Husson et al., 2011)), critical differences in how forces are applied may allow BATTLES to more accurately mimic in vivo physiology. First, while polystyrene or silica beads used in optical trapping assays distribute applied forces across all formed pMHC/TCR interactions at the interface, 'smart beads' apply force locally via pMHCs attached to PNIPAm filaments within the bead hydrogel matrix. This geometry, analogous to interactions between APCpresented pMHCs and protrusive T-cell microvilli prior to activation (Ghosh et al., 2020), may prevent dissipation of intramolecular forces at higher pMHC densities. Second, the duration of the force ramp applied by 'smart beads' over $60 \mathrm{~s}$ of cooling and associated swelling may allow peptides with a fast 2D on-rate to iteratively rupture and rebind, driving dynamic (Pryshchep et al., 2014) and reversible $\sim 10 \mathrm{~nm}$ structural transitions within the TCR/pMHC complex (Das et al., 2016). Such energized work (10 nm transitions under 10-15 pN loads = $\sim 100$ to $150 \mathrm{pN} \cdot \mathrm{nm}$ or hydrolysis of $\sim 2$ ATPs) may lead to a stronger and more sustainable $\mathrm{Ca}^{2+}$ flux (Feng et al., 2017) similar to that observed for naïve T cells (Christo et al., 2015). Moreover, this mechanical work has been proposed to exponentially amplify the reaction rate value for antigenic pMHCs (Feng et al., 2018), potentially explaining the observed physiological discrimination ratio of 10,000-100,000 for non-self vs. self pMHCs. 
The TCR-transduced T cell lines employed in typical high-throughput screens are less sensitive than primary $T$ cells, requiring APC pulsing with high peptide concentrations $(\sim 1 \mu \mathrm{M})$. However, several lines of evidence suggest that peptide sequences identified in screens at relatively high densities may not represent the most promising antigen vaccine candidates. The identity of synthetic peptide sequences capable of stimulating IL-2 cytokine release and CD69 expression for crawling primary T cell blasts (Wolf et al., 2003) displaying 2B4 and 5cc7 TCRs (Birnbaum et al., 2014) depends on the concentration at which they are displayed, consistent with the concentration multiplexing BATTLES results presented here. The ability to accurately identify and discriminate potent agonists presented at low pMHC concentrations even when using TCRtransduced SKW3 T cell lines suggests that BATTLES could be a bona fide proxy to screening primary T cells.

Overall, we anticipate that BATTLES can be applied to a wide range of future questions beyond obtaining a basic understanding the structure-activity relationships and physical mechanisms that drive 'catch bond' formation. While here we assay only 21 peptides, lanthanide-based spectral encoding has previously yielded $>1,100$ codes (Nguyen et al., 2017), suggesting BATTLES can be applied to much larger libraries in the future. In medicine, BATTLES can be used as a platform for investigating the force response of multiple engineered T cells bearing either mutant TCRs or chimeric antigen receptor (CARs) (Gross et al., 1989) as well as to enhance the potency of peptide vaccines to a therapeutic TCR by directly probing a peptide library generated from either pMHC tetramer binding or pMHC yeast display. Finally, BATTLES could be applied as a general mechanobiology tool for a wide range of mechanosensitive systems beyond T cells, ranging from other immune cells to adhesion cells and even neurons (Chen et al., 2017).

\section{ACKNOWLEDGEMENTS}

This work was supported by NIH grants 1DP2GM123641, R01GM107132 and a Stanford Bio-X Interdisciplinary Initiatives seed grant. K.C.G. is an investigator of the Howard Hughes Medical Institute, and is also supported by NIH-5R01Al103867, U19AI057229, Mathers Foundation, and Ludwig Foundation support. P.M.F. is a Chan Zuckerberg Biohub Investigator and acknowledges the support of a Sloan Research Foundation Fellowship. Y.F. is a Cancer Research Institute Postdoctoral Fellow. X.Z is funded by a Stanford Bio-X seed grant. A.K.W was funded by the Natural Sciences and Engineering Research Council of Canada Postdoctoral Fellowship. Part of this work was performed at the Stanford Nano Shared Facilities (SNSF), supported by the National Science Foundation under award ECCS-1542152. The authors would also like to thank Dr. E. Appel and D. Chan for helpful discussions concerning polymers and help with shear modulus measurement, and Dr. Z. Bryant and Dr. P.V. Ruijgrok for help with TIRF microscopy.

\section{AUTHOR CONTRIBUTIONS}

Y.F. conceptualized the platform and validation experiments; X.Z. made all the T cell lines and UV-liable pMHC folding. Y.F., X.Z., and A.K.W. analyzed data; K.C.G and P.M.F. provided funding, resources, mentorship, and project supervision. Y.F., X.Z., A.K.W., K.C.G. and P.M.F. wrote the paper.

\section{DECLARATION OF INTERESTS}

Stanford University and Chan Zuckerberg Biohub have filed a provisional patent application (U.S. Provisional Patent application No. 63/108,162) on the BATTLES technology described here, and Y.F., X.Z., A.K.W., K.C.G. and P.M.F. are named inventors.

\section{REFERENCES}

Bashour, K.T., Gondarenko, A., Chen, H., Shen, K., Liu, X., Huse, M., Hone, J.C., and Kam, L.C. (2014). CD28 and CD3 have complementary roles in T-cell traction forces. Proceedings of the National Academy of Sciences 111, 2241-2246.

Basu, R., Whitlock, B.M., Husson, J., Le Floc'h, A., Jin, W., Oyler-Yaniv, A., Dotiwala, F., Giannone, G., Hivroz, C., and Biais, N. (2016). Cytotoxic T cells use mechanical force to potentiate target cell killing.

Cell 165, 100-110. 
Bentzen, A.K., Marquard, A.M., Lyngaa, R., Saini, S.K., Ramskov, S., Donia, M., Such, L., Furness, A.J.S., McGranahan, N., Rosenthal, R., et al. (2016). Large-scale detection of antigen-specific T cells using peptide-MHC-I multimers labeled with DNA barcodes. Nature Biotechnology 34, 1037-1045.

Bentzen, A.K., Such, L., Jensen, K.K., Marquard, A.M., Jessen, L.E., Miller, N.J., Church, C.D., Lyngaa, R., Koelle, D.M., Becker, J.C., et al. (2018). T cell receptor fingerprinting enables in-depth characterization of the interactions governing recognition of peptide-MHC complexes. Nature Biotechnology 36, 1191-1196.

Birnbaum, M.E., Mendoza, J.L., Sethi, D.K., Dong, S., Glanville, J., Dobbins, J., Özkan, E., Davis, M.M., Wucherpfennig, K.W., and Garcia, K.C. (2014). Deconstructing the peptide-MHC specificity of T cell recognition. Cell 157, 1073-1087.

Brazin, K.N., Mallis, R.J., Boeszoermenyi, A., Feng, Y., Yoshizawa, A., Reche, P.A., Kaur, P., Bi, K., Hussey, R.E., and Duke-Cohan, J.S. (2018). The T cell antigen receptor a transmembrane domain coordinates triggering through regulation of bilayer immersion and CD3 subunit associations. Immunity 49, 829-841. e826.

Burmistrova, A., Richter, M., Eisele, M., Üzüm, C., and Von Klitzing, R. (2011). The effect of co-monomer content on the swelling/shrinking and mechanical behaviour of individually adsorbed PNIPAM microgel particles. Polymers 3, 1575-1590.

Chandorkar, Y., Castro Nava, A., Schweizerhof, S., Van Dongen, M., Haraszti, T., Köhler, J., Zhang, H., Windoffer, R., Mourran, A., Möller, M., et al. (2019). Cellular responses to beating hydrogels to investigate mechanotransduction. Nature Communications 10, 4027.

Chen, Y., Ju, L., Rushdi, M., Ge, C., and Zhu, C. (2017). Receptor-mediated cell mechanosensing. Molecular biology of the cell 28, 3134-3155.

Chodon, T., Comin-Anduix, B., Chmielowski, B., Koya, R.C., Wu, Z., Auerbach, M., Ng, C., Avramis, E., Seja, E., Villanueva, A., et al. (2014). Adoptive Transfer of MART-1 T-Cell Receptor Transgenic Lymphocytes and Dendritic Cell Vaccination in Patients with Metastatic Melanoma. Clinical Cancer Research 20, 2457.

Christo, S.N., Diener, K.R., Nordon, R.E., Brown, M.P., Griesser, H.J., Vasilev, K., Christo, F.C., and Hayball, J.D. (2015). Scrutinizing calcium flux oscillations in T lymphocytes to deduce the strength of stimulus. Scientific Reports 5, 7760.

Corse, E., Gottschalk, R.A., Krogsgaard, M., and Allison, J.P. (2010). Attenuated T cell responses to a high-potency ligand in vivo. PLoS Biol 8, e1000481.

Das, D.K., Feng, Y., Mallis, R.J., Li, X., Keskin, D.B., Hussey, R.E., Brady, S.K., Wang, J.-H., Wagner, G., Reinherz, E.L., et al. (2015). Force-dependent transition in the T-cell receptor $\beta$-subunit allosterically regulates peptide discrimination and $\mathrm{pMHC}$ bond lifetime. Proceedings of the National Academy of Sciences 112, 1517-1522.

Das, D.K., Mallis, R.J., Duke-Cohan, J.S., Hussey, R.E., Tetteh, P.W., Hilton, M., Wagner, G., Lang, M.J., and Reinherz, E.L. (2016). Pre-T cell receptors (pre-TCRs) leverage V $\beta$ complementarity determining regions (CDRs) and hydrophobic patch in mechanosensing thymic self-ligands. Journal of Biological Chemistry 291, 25292-25305.

Ding, T., Valev, V.K., Salmon, A.R., Forman, C.J., Smoukov, S.K., Scherman, O.A., Frenkel, D., and Baumberg, J.J. (2016). Light-induced actuating nanotransducers. Proceedings of the National Academy of Sciences 113, 5503-5507.

Dustin, M.L., and Groves, J.T. (2012). Receptor Signaling Clusters in the Immune Synapse. Annual Review of Biophysics 41, 543-556.

Feng, Y., Brazin, K.N., Kobayashi, E., Mallis, R.J., Reinherz, E.L., and Lang, M.J. (2017). Mechanosensing drives acuity of $\alpha \beta$ T-cell recognition. Proceedings of the National Academy of Sciences 114, E8204-E8213.

Feng, Y., Reinherz, E.L., and Lang, M.J. (2018). a $\mathrm{\beta}$ T Cell Receptor Mechanosensing Forces out Serial Engagement. Trends Immunol 39, 596-609.

Feng, Y., White, A.K., Hein, J.B., Appel, E.A., and Fordyce, P.M. (2020). MRBLES 2.0: High-throughput generation of chemically functionalized spectrally and magnetically encoded hydrogel beads using a simple single-layer microfluidic device. Microsystems \& Nanoengineering 6, 109. 
Freedman, M. (1979). Early biochemical events in lymphocyte activation: I. Investigations on the nature and significance of early calcium fluxes observed in mitogen-induced $T$ and $B$ lymphocytes. Cellular immunology 44, 290-313.

Fritzsche, M., Fernandes, R.A., Chang, V.T., Colin-York, H., Clausen, M.P., Felce, J.H., Galiani, S., Erlenkämper, C., Santos, A.M., Heddleston, J.M., et al. (2017). Cytoskeletal actin dynamics shape a ramifying actin network underpinning immunological synapse formation. Science Advances 3, e1603032. Gerver, R.E., Gómez-Sjöberg, R., Baxter, B.C., Thorn, K.S., Fordyce, P.M., Diaz-Botia, C.A., Helms, B.A., and DeRisi, J.L. (2012). Programmable microfluidic synthesis of spectrally encoded microspheres. Lab on a Chip 12, 4716-4723.

Ghosh, S., Di Bartolo, V., Tubul, L., Shimoni, E., Kartvelishvily, E., Dadosh, T., Feigelson, S.W., Alon, R., Alcover, A., and Haran, G. (2020). ERM-Dependent Assembly of T Cell Receptor Signaling and Costimulatory Molecules on Microvilli prior to Activation. Cell Reports 30, 3434-3447.e3436.

Grakoui, A., Bromley, S.K., Sumen, C., Davis, M.M., Shaw, A.S., Allen, P.M., and Dustin, M.L. (1999). The immunological synapse: a molecular machine controlling T cell activation. Science 285, 221-227. Gross, G., Gorochov, G., Waks, T., and Eshhar, Z. (1989). Generation of effector T cells expressing chimeric $T$ cell receptor with antibody type-specificity. Paper presented at: Transplantation proceedings. Hanson, D. (1993). Fever and the immune response. The effects of physiological temperatures on primary murine splenic T-cell responses in vitro. The Journal of Immunology 151, 436-448.

Harink, B., Nguyen, H., Thorn, K., and Fordyce, P. (2019). An open-source software analysis package for Microspheres with Ratiometric Barcode Lanthanide Encoding (MRBLEs). PloS one 14, e0203725.

Henrickson, S.E., Mempel, T.R., Mazo, I.B., Liu, B., Artyomov, M.N., Zheng, H., Peixoto, A., Flynn, M.P., Senman, B., and Junt, T. (2008). T cell sensing of antigen dose governs interactive behavior with dendritic cells and sets a threshold for T cell activation. Nature immunology 9, 282-291.

$\mathrm{Hu}, \mathrm{K} . \mathrm{H}$., and Butte, M.J. (2016). T cell activation requires force generation. Journal of Cell Biology 213, 535-542.

Huang, J., Brameshuber, M., Zeng, X., Xie, J., Li, Q.-j., Chien, Y.-h., Valitutti, S., and Davis, M.M. (2013). A single peptide-major histocompatibility complex ligand triggers digital cytokine secretion in CD4+ T cells. Immunity 39, 846-857.

Huang, J., Zarnitsyna, V.I., Liu, B., Edwards, L.J., Jiang, N., Evavold, B.D., and Zhu, C. (2010). The kinetics of two-dimensional TCR and pMHC interactions determine T-cell responsiveness. Nature 464, 932-936.

Hui, K.L., Balagopalan, L., Samelson, L.E., and Upadhyaya, A. (2015). Cytoskeletal forces during signaling activation in Jurkat T-cells. Molecular biology of the cell 26, 685-695.

Huse, M. (2017). Mechanical forces in the immune system. Nature Reviews Immunology 17, 679-690. Husson, J., Chemin, K., Bohineust, A., Hivroz, C., and Henry, N. (2011). Force generation upon T cell receptor engagement. PloS one 6, e19680.

Joglekar, A.V., Leonard, M.T., Jeppson, J.D., Swift, M., Li, G., Wong, S., Peng, S., Zaretsky, J.M., Heath, J.R., Ribas, A., et al. (2019). T cell antigen discovery via signaling and antigen-presenting bifunctional receptors. Nature Methods 16, 191-198.

Keskin, D.B., Reinhold, B.B., Zhang, G.L., Ivanov, A.R., Karger, B.L., and Reinherz, E.L. (2015). Physical detection of influenza $A$ epitopes identifies a stealth subset on human lung epithelium evading natural CD8 immunity. Proceedings of the National Academy of Sciences 112, 2151-2156.

Kim, J., and Hayward, R.C. (2012). Mimicking dynamic in vivo environments with stimuli-responsive materials for cell culture. Trends in Biotechnology 30, 426-439.

Kim, S.T., Takeuchi, K., Sun, Z.-Y.J., Touma, M., Castro, C.E., Fahmy, A., Lang, M.J., Wagner, G., and Reinherz, E.L. (2009). The aß T cell receptor is an anisotropic mechanosensor. Journal of Biological Chemistry 284, 31028-31037.

Kula, T., Dezfulian, M.H., Wang, C.I., Abdelfattah, N.S., Hartman, Z.C., Wucherpfennig, K.W., Lyerly, H.K., and Elledge, S.J. (2019). T-scan: a genome-wide method for the systematic discovery of T cell epitopes. Cell 178, 1016-1028. e1013.

Lau, A., Portigliatti, M., Raphaël, E., and Léger, L. (2002). Spreading of latex particles on a substrate. EPL (Europhysics Letters) 60, 717. 
Lei, K., Kurum, A., and Tang, L. (2020). Mechanical Immunoengineering of T cells for Therapeutic Applications. Accounts of Chemical Research, 707-716.

Li, G., Bethune, M.T., Wong, S., Joglekar, A.V., Leonard, M.T., Wang, J.K., Kim, J.T., Cheng, D., Peng, S., Zaretsky, J.M., et al. (2019). T cell antigen discovery via trogocytosis. Nature Methods 16, 183-190. Li, Y.-C., Chen, B.-M., Wu, P.-C., Cheng, T.-L., Kao, L.-S., Tao, M.-H., Lieber, A., and Roffler, S.R. (2010). Cutting Edge: mechanical forces acting on T cells immobilized via the TCR complex can trigger TCR signaling. The Journal of Immunology 184, 5959-5963.

Liu, B., Chen, W., Evavold, B.D., and Zhu, C. (2014). Accumulation of dynamic catch bonds between TCR and agonist peptide-MHC triggers T cell signaling. Cell 157, 357-368.

Liu, Y., Blanchfield, L., Ma, V.P.-Y., Andargachew, R., Galior, K., Liu, Z., Evavold, B., and Salaita, K. (2016a). DNA-based nanoparticle tension sensors reveal that T-cell receptors transmit defined pN forces to their antigens for enhanced fidelity. Proceedings of the National Academy of Sciences 113, 5610-5615. Liu, Z., Liu, Y., Chang, Y., Seyf, H.R., Henry, A., Mattheyses, A.L., Yehl, K., Zhang, Y., Huang, Z., and Salaita, K. (2016b). Nanoscale optomechanical actuators for controlling mechanotransduction in living cells. Nature methods 13, 143-146.

Lyons, D.S., Lieberman, S.A., Hampl, J., Boniface, J.J., Chien, Y.-h., Berg, L.J., and Davis, M.M. (1996). A TCR binds to antagonist ligands with lower affinities and faster dissociation rates than to agonists. Immunity 5, 53-61.

Ma, Z., Sharp, K.A., Janmey, P.A., and Finkel, T.H. (2008). Surface-anchored monomeric agonist pMHCs alone trigger TCR with high sensitivity. PLoS Biol 6, e43.

Meng, K.P., Majedi, F.S., Thauland, T.J., and Butte, M.J. (2020). Mechanosensing through YAP controls T cell activation and metabolism. Journal of Experimental Medicine 217.

Nguyen, H.Q., Baxter, B.C., Brower, K., Diaz-Botia, C.A., DeRisi, J.L., Fordyce, P.M., and Thorn, K.S. (2017). Programmable Microfluidic Synthesis of Over One Thousand Uniquely Identifiable Spectral Codes. Advanced optical materials 5, 1600548.

Pryshchep, S., Zarnitsyna, V.I., Hong, J., Evavold, B.D., and Zhu, C. (2014). Accumulation of serial forces on TCR and CD8 frequently applied by agonist antigenic peptides embedded in MHC molecules triggers calcium in T cells. J Immunol 193, 68-76.

Purbhoo, M.A., Irvine, D.J., Huppa, J.B., and Davis, M.M. (2004). T cell killing does not require the formation of a stable mature immunological synapse. Nature immunology 5, 524-530.

Riley, T.P., Hellman, L.M., Gee, M.H., Mendoza, J.L., Alonso, J.A., Foley, K.C., Nishimura, M.I., Vander Kooi, C.W., Garcia, K.C., and Baker, B.M. (2018). T cell receptor cross-reactivity expanded by dramatic peptide-MHC adaptability. Nature chemical biology 14, 934-942.

Ritter, A.T., Asano, Y., Stinchcombe, J.C., Dieckmann, N., Chen, B.-C., Gawden-Bone, C., van Engelenburg, S., Legant, W., Gao, L., and Davidson, M.W. (2015). Actin depletion initiates events leading to granule secretion at the immunological synapse. Immunity 42, 864-876.

Rodenko, B., Toebes, M., Hadrup, S.R., Van Esch, W.J., Molenaar, A.M., Schumacher, T.N., and Ovaa, $\mathrm{H}$. (2006). Generation of peptide-MHC class I complexes through UV-mediated ligand exchange. Nature protocols 1, 1120 .

Sasada, T., Ghendler, Y., Wang and, J.-h., and Reinherz, E.L. (2000). Thymic selection is influenced by subtle structural variation involving the $\mathrm{p} 4$ residue of an $\mathrm{MHC}$ class I-bound peptide. European Journal of Immunology 30, 1281-1289.

Sibener, L.V., Fernandes, R.A., Kolawole, E.M., Carbone, C.B., Liu, F., McAffee, D., Birnbaum, M.E., Yang, X., Su, L.F., Yu, W., et al. (2018). Isolation of a Structural Mechanism for Uncoupling T Cell

Receptor Signaling from Peptide-MHC Binding. Cell 174, 672-687.e627.

Stone, J.D., Chervin, A.S., and Kranz, D.M. (2009). T $\square$ cell receptor binding affinities and kinetics: impact on T $\square$ cell activity and specificity. Immunology 126, 165-176.

Ueno, T., Tomiyama, H., Fujiwara, M., Oka, S., and Takiguchi, M. (2004). Functionally Impaired HIVSpecific CD8 T Cells Show High Affinity TCR-Ligand Interactions. The Journal of Immunology 173, 54515457.

Wei, X., Tromberg, B.J., and Cahalan, M.D. (1999). Mapping the sensitivity of T cells with an optical trap: polarity and minimal number of receptors for $\mathrm{Ca}(2+)$ signaling. Proc Natl Acad Sci U S A 96, 8471-8476. 
bioRxiv preprint doi: https://doi.org/10.1101/2021.04.24.441194; this version posted April 26, 2021. The copyright holder for this preprint (which

was not certified by peer review) is the author/funder, who has granted bioRxiv a license to display the preprint in perpetuity. It is made available under aCC-BY-NC-ND 4.0 International license.

WoldeMussie, E., Maeyama, K., and Beaven, M. (1986). Loss of secretory response of rat basophilic leukemia (2H3) cells at 40 degrees $\mathrm{C}$ is associated with reversible suppression of inositol phospholipid breakdown and calcium signals. The Journal of Immunology 137, 1674-1680.

Wolf, K., Mu $\square$ ller, R., Borgmann, S., Bro $\square$ cker, E.-B., and Friedl, P. (2003). Amoeboid shape change and contact guidance: T-lymphocyte crawling through fibrillar collagen is independent of matrix remodeling by MMPs and other proteases. Blood 102, 3262-3269.

Wu, P.-H., Aroush, D.R.-B., Asnacios, A., Chen, W.-C., Dokukin, M.E., Doss, B.L., Durand-Smet, P., Ekpenyong, A., Guck, J., and Guz, N.V. (2018). A comparison of methods to assess cell mechanical properties. Nature methods 15, 491-498.

Wülfing, C., and Davis, M.M. (1998). A receptor/cytoskeletal movement triggered by costimulation during T cell activation. Science 282, 2266-2269.

Zehn, D., Cohen, C.J., Reiter, Y., and Walden, P. (2006). Efficiency of peptide presentation by dendritic cells compared with other cell types: implications for cross-priming. International Immunology 18, 16471654.

Zhang, S.-Q., Ma, K.-Y., Schonnesen, A.A., Zhang, M., He, C., Sun, E., Williams, C.M., Jia, W., and Jiang, N. (2018). High-throughput determination of the antigen specificities of $T$ cell receptors in single cells. Nature Biotechnology 36, 1156-1159. 


\section{FIGURES AND FIGURE CAPTIONS}
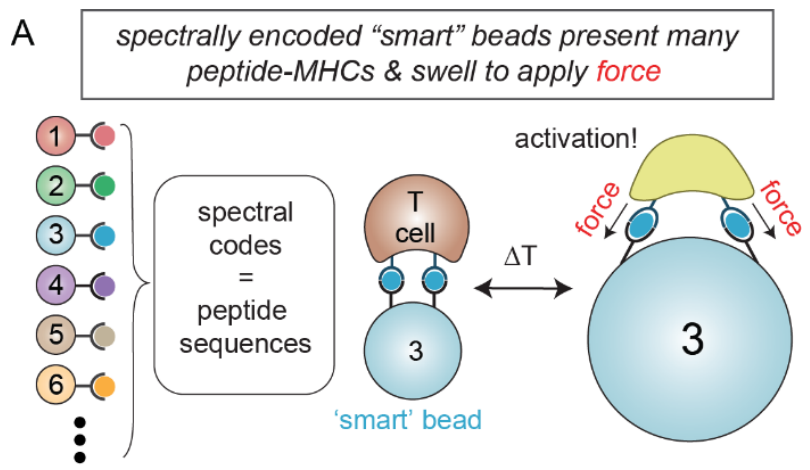

B

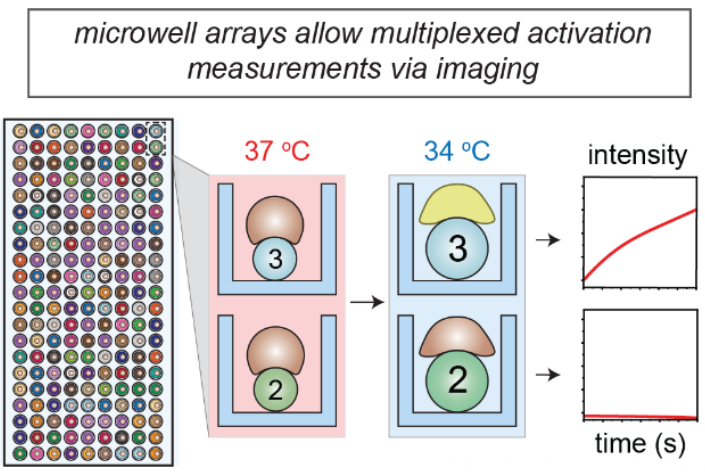

C

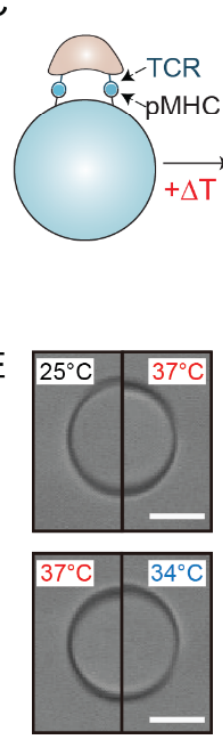

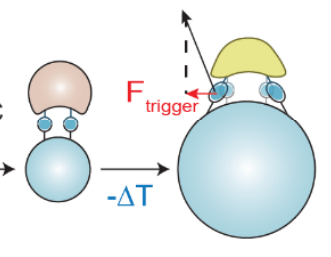
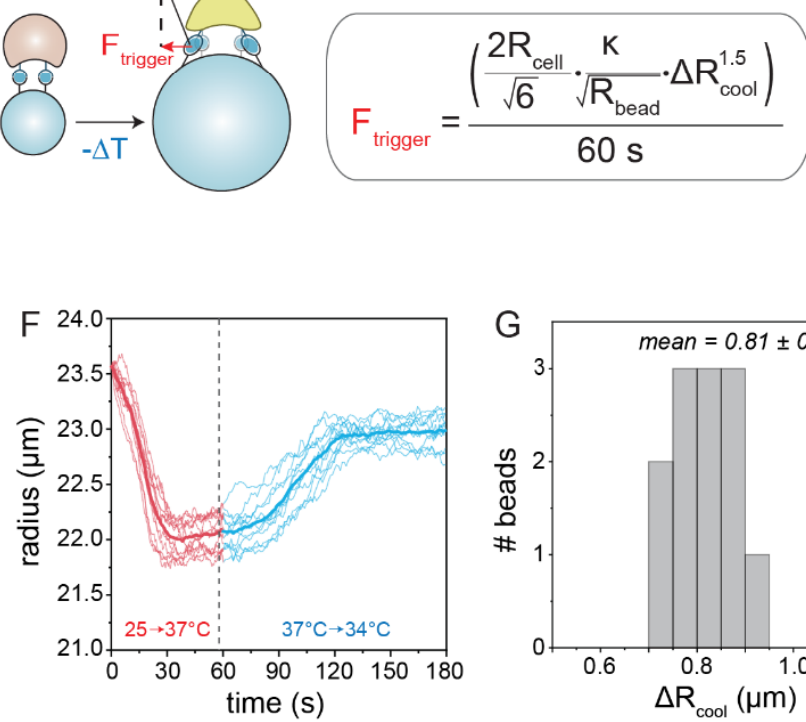

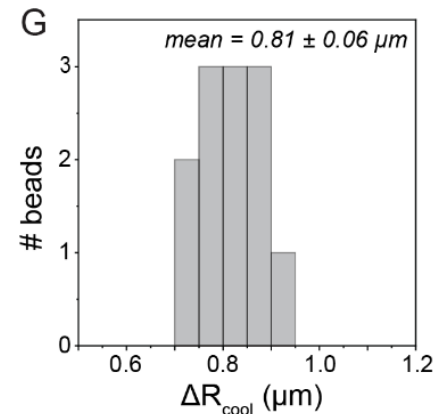

Figure 1. Overview of BATTLES assay and 'smart beads'. (A) BATTLES applies shear forces to pMHC/TCR interactions at cell surfaces via thermally responsive 'smart beads' that are spectrally encoded (with a 1:1 linkage between embedded spectral code and presented pMHC sequence, presented pMHC density, or the magnitude of the applied load). (B) By loading $T$ cells onto the surfaces of 'smart beads' loaded into microwell arrays, BATTLES allows for high-throughput single-cell measurement of $\mathrm{T}$ cell responses (cellular $\mathrm{Ca}^{2+}$ flux) via microscopy after the application of force. (C) Schematic and formula detailing how thermal bead expansion applies force to pMHC/TCR interactions at cell surface; $R_{\text {cell }}$ is the T cell radius $(\sim 4 \mu \mathrm{m}), \kappa$ is the modulus of rigidity of the 'smart bead', $R_{\text {bead }}$ is the radius of the bead prior to heating, and $\Delta R_{\text {bead }}$ is the change in bead radius upon cooling from $37^{\circ} \mathrm{C}$ to $34^{\circ} \mathrm{C}$. Force ramps are calculated assuming beads swell over $60 \mathrm{~s}$ after cooling. (D) Cartoon schematic of polymeric 'smart bead' matrix. (E) Representative bright field images showing the change in radius for a 'smart bead' upon heating $\left(25\right.$ to $\left.37^{\circ} \mathrm{C}\right)$ and cooling $\left(37\right.$ to $\left.34^{\circ} \mathrm{C}\right)$. Scale bar: $25 \mu \mathrm{m}$. (F,G) Measured bead radii $(F)$ and changes in radii $(G)$ over time for 12 beads upon heating and cooling. $(\mathbf{H})$ Calculated expansion forces for 12 beads. 

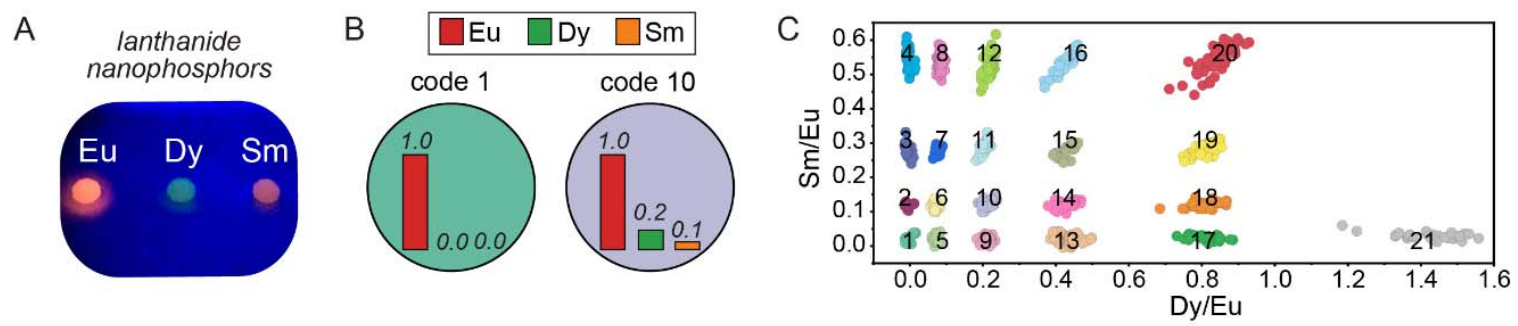

E peptide/HLA-B35 library (1) VPLTEDSLL (12) VPLSEDSLL (2) VPLTEDSIL (13) VPIVEDSEL (3) VPVVEDALM (14) VPLIDDSFL (4) VPVTEDIDL (15) VPLVEDSMM (5) VPLTEDVIF (16) VPIMEDSLI (6) VPIMEDSPI (1) IPLTEEAEL (7) VPLLEDSLL (18) VPLVEDPFI (8) VPLTEDALL (19) VPLVEDSIF (9) GPAPAYHQY (2) VPITEDSQL (10) VPFIEDSFL (2) VPLTEDAEL (1) VPVIEDATL

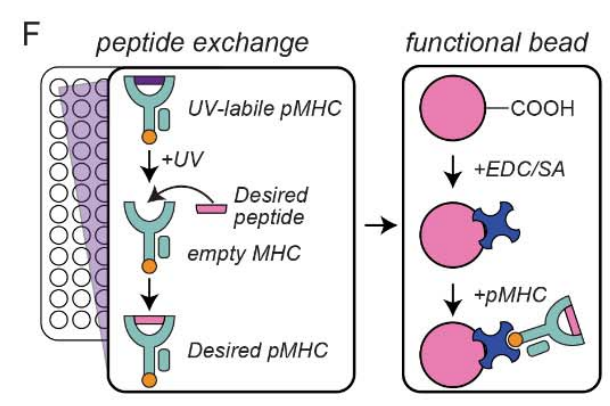

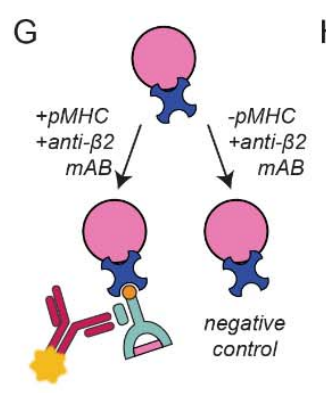
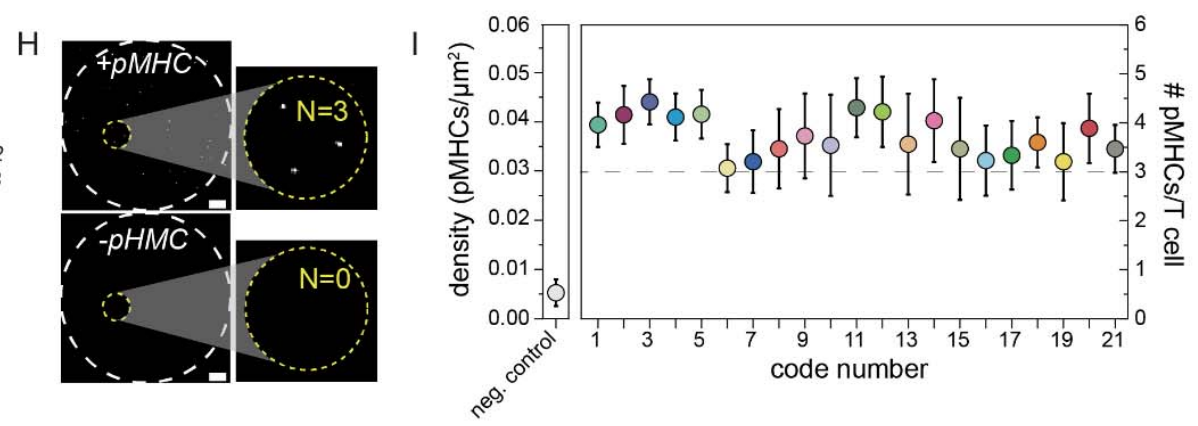

Figure 2. 'Smart beads' can display 21 different peptide sequences at physiological densities. (A) Image of polymer droplets containing 3 different Ln species (Eu, Dy, and Sm) upon excitation with a UV LED lamp (wavelength $=285 \mathrm{~nm}$ ). (B) Cartoon schematic showing 2 example ratiometric codes. (C) Measured median Ln ratios (colored markers) for 872 beads containing equal amounts of Eu and 21 different combinations of Sm and Dy along with the expected target ratios. (D) Structural schematic and peptide sequence for 21 peptides previously shown to bind TCR55 cells in yeast display experiments ${ }^{20}$; blue and orange residues denote TCR and MHC anchor contacts, respectively. (E) Sequences of HIVpol-derived peptides coupled to 'smart beads' containing particular spectral codes. (F) Schematics detailing UV-exchange method to generate biotinylated pMHCs bearing desired peptides within the MHC groove (left) and coupling of biotinylated pMHCs to 'smart beads' bearing streptavidin covalently attached to carboxyl groups via EDC chemistry (right). (G) Schematics detailing the quantification of the interfacial densities of presented pMHC molecules via TIRF microscopy using fluorescently labeled antibodies to detect peptide-loaded MHC complexes. (H) TIRF images for an example pMHC-coated bead (code $8,+\mathrm{pMHC}$ ) and an example negative control bead (-pMHC). White dashed circles denote the bead circumference settled on the slide surface (diameter $\sim 50 \mu \mathrm{m}$ ); yellow circles denote the size of an average T cell; numbers indicate identified pMHCs within yellow circles. (I) Estimated surface density (left) and number of pMHCs/cell (right) from surface density measurements across all 'smart bead' codes; markers denote means and error bars denote standard deviation. The dashed line represents the physiological number of pMHCs per cell (Henrickson et al., 2008). 

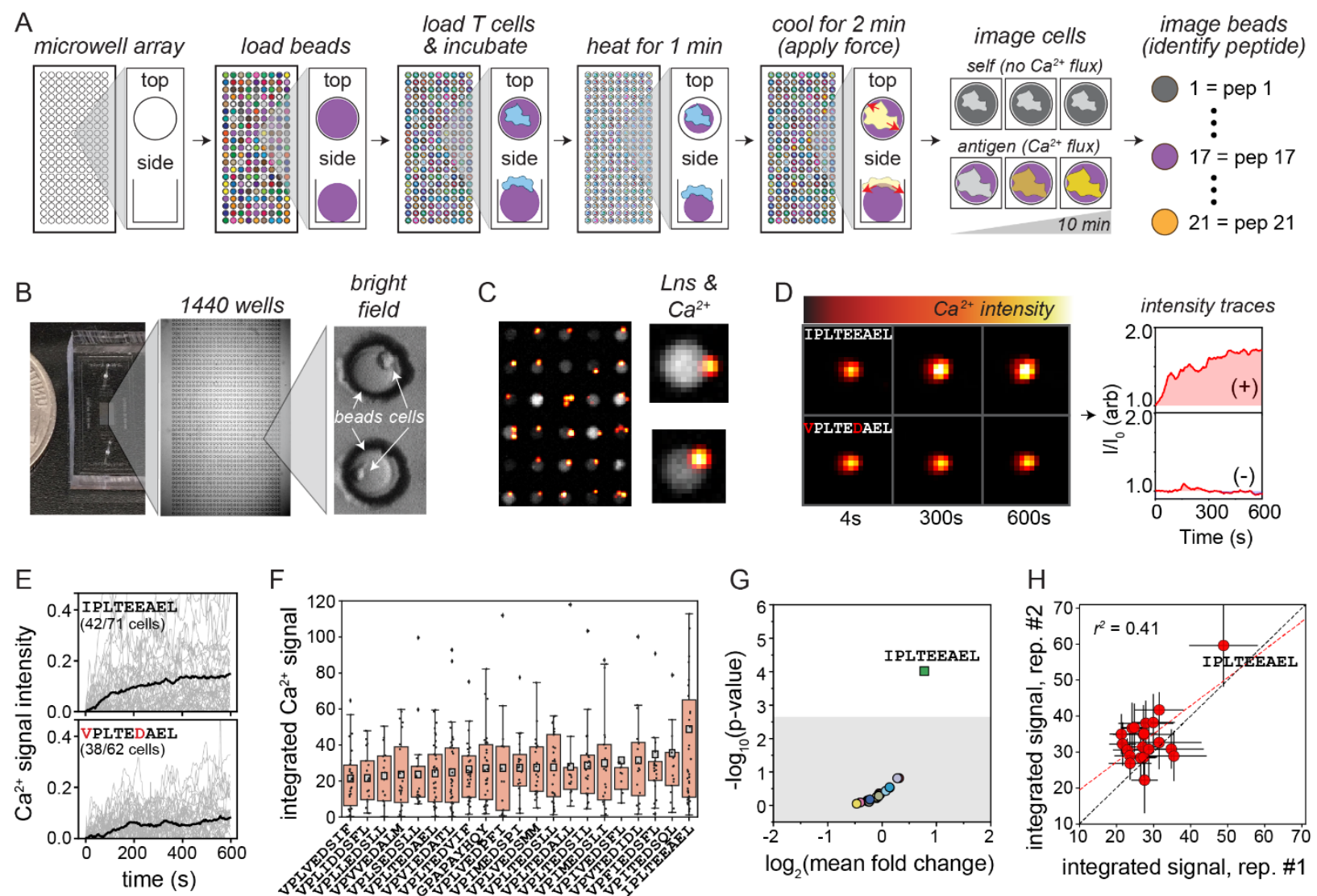

Figure 3. Activation responses for TCR589-transduced T cells interacting with 21-peptide library. (A) Cartoon schematic of BATTLES workflow and expected results. (B) Representative bright field images of the 1440 well microwell device containing 'smart beads' and loaded T cells. (C) Representative merged lanthanide and fluorescence images of 'smart beads' and associated T cells in the presence of a $\mathrm{Ca}^{2+}$ sensitive dye. (D) Representative images (left) and processed intensity traces (right) quantifying $\mathrm{Ca}^{2+}$ flux within single TCR589 T cells interacting with pMHC-coated 'smart beads' bearing the stimulatory HIVpol peptide (IPLTEEAEL) (top) and a nonstimulatory peptide (VPLTEDAEL) (bottom). (E) $\mathrm{Ca}^{2+}$ signal intensity as a function of time for all positive single cells $\left(\int\left(1 / l_{0}-1\right)>0\right)$ (light grey); mean signal intensity over time is shown in black. $(\mathbf{F})$ Integrated $\mathrm{Ca}^{2+}$ signals for all positive single cells as a function of peptide sequence. Individual cell signals are shown as black markers; box lower and upper limits indicate $25^{\text {th }}$ and $75^{\text {th }}$ percentiles, respectively. Grey squares represent the mean values. (G) Estimated p-value (calculated via bootstrapping, see Methods) vs. the log2-transformed mean fold change for integrated $\mathrm{Ca}^{2+}$ signals for each peptide sequence. Grey box indicates Bonferroni-corrected $p$-value at a significance of $0.05(\mathrm{p}=0.0024)$. $(\mathbf{H})$ Integrated $\mathrm{Ca}^{2+}$ signals for each peptide across 2 replicates. Markers indicate mean; error bars indicate SEM; dashed black line indicates the 1:1 line; red dashed line indicates a linear regression. 
A

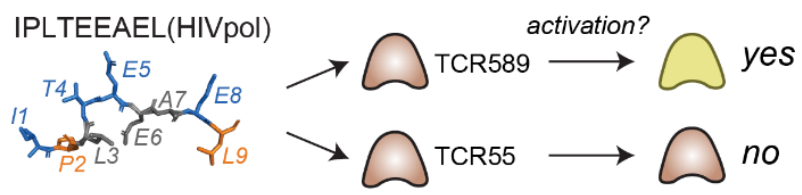

B

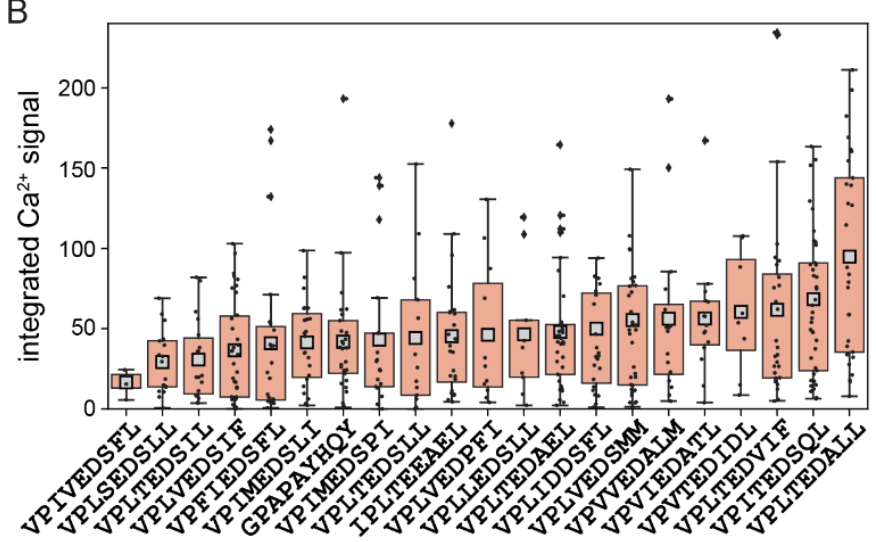

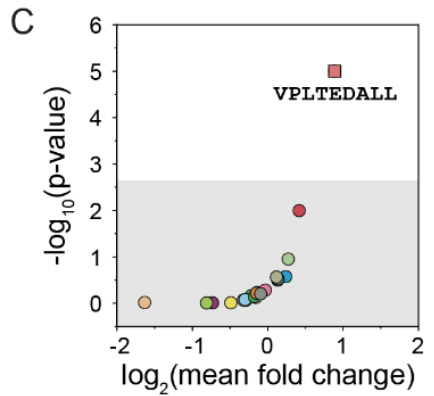

D

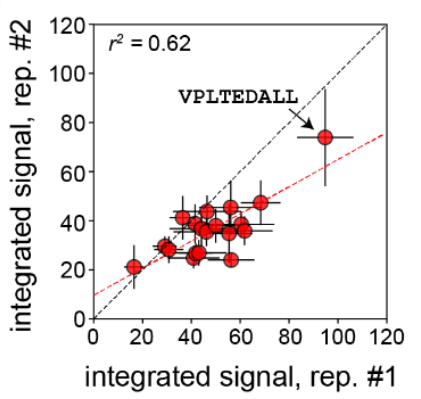

Figure 4. Activation responses for TCR55-transduced T cells interacting with 21 peptide library. (A) Schematic illustrating previously observed divergent cellular reactivity responses for TCR55 vs. TCR589 interacting with the HIVpol-derived peptide. (B) Integrated $\mathrm{Ca}^{2+}$ signals for positive cells across all peptide sequences tested. Integrated signals for individual cells are shown as black markers; box lower and upper limits represent $25^{\text {th }}$ and $75^{\text {th }}$ percentiles, respectively. Grey squares represent the mean values. (C) Estimated p-value (calculated via bootstrapping, see Methods) vs. the log2-transformed mean fold change for integrated $\mathrm{Ca}^{2+}$ signals for each peptide sequence; Grey box indicates Bonferronicorrected $p$-value at a significance of 0.05 ( $p=0.0024)$. (D) Integrated $\mathrm{Ca}^{2+}$ signals for each peptide across 2 replicates. Markers indicate mean; error bars indicate SEM; dashed black line indicates the 1:1 line; red dashed line indicates a linear regression. 

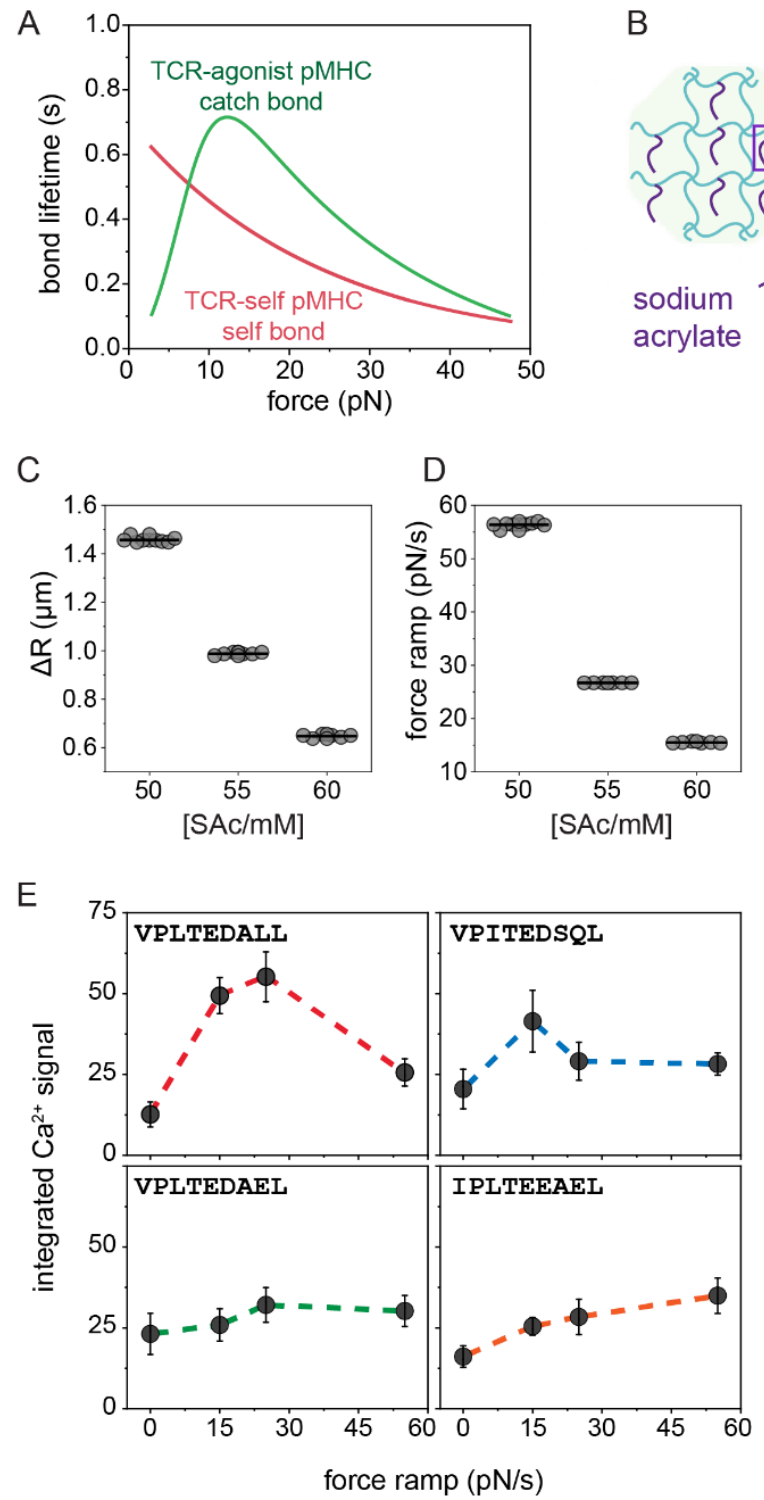

B
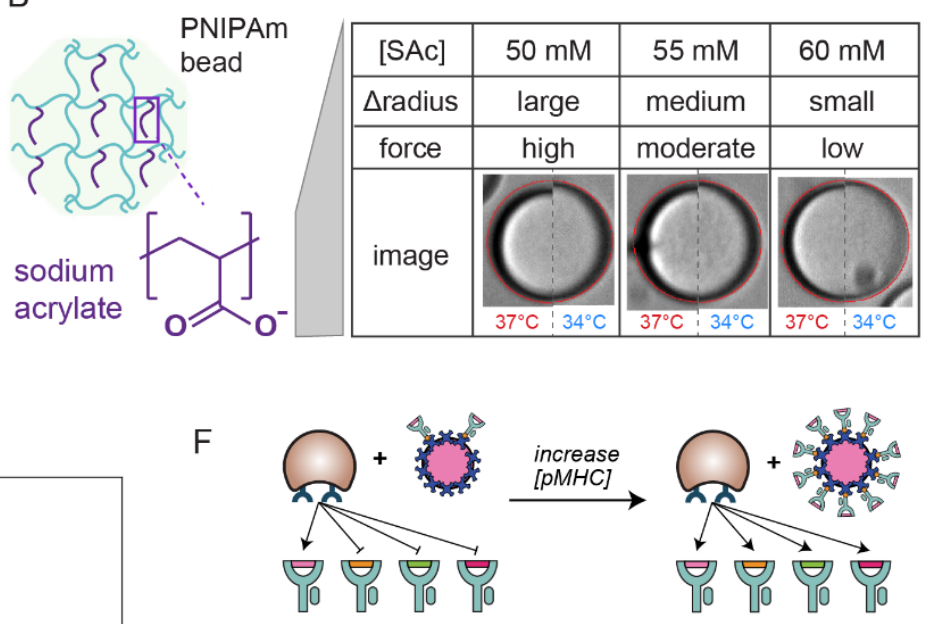

G
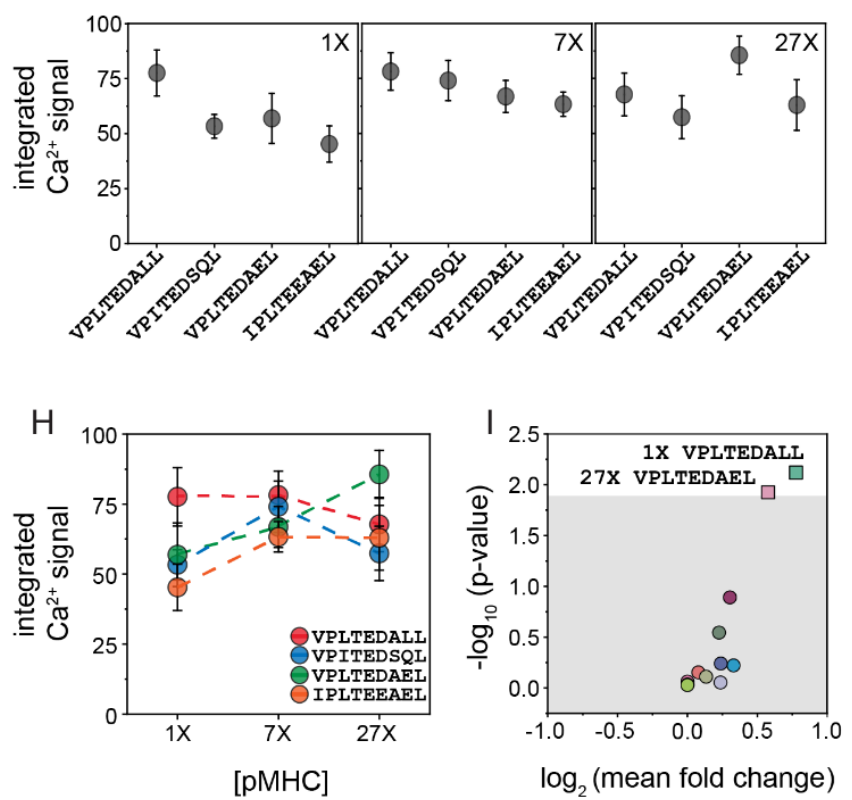

Figure 5. Multiplexing sequence, applied force, and displayed pMHC densities using BATTLES. (A) Typical catch/slip bond lifetime profiles. (B) Schematic and images indicating that change in bead radius depends on the amount of sodium acrylate (SAC) within the 'smart bead' matrix. (C) Measured changes in bead radius upon cooling from $37^{\circ} \mathrm{C}$ to $34^{\circ} \mathrm{C}$ for 3 codes $(9,6$, and 6 beads/code) containing different SAc concentrations. (D) Calculated expansion forces for 'smart beads' in $\mathbf{C}$ based on measurements of bead radii, changes in bead radii, and the rigidity of the NIPAM slab. (E) Mean integrated $\mathrm{Ca}^{2+}$ signals for positive cells interacting with VPLTEDALL, VPITEDSQL, VPLTEDAEL and IPLTEEAEL peptides at low $(\sim 15 \mathrm{pN} / \mathrm{s})$, moderate ( $25 \mathrm{pN} / \mathrm{s})$ and high $(\sim 55 \mathrm{pN} / \mathrm{s})$ force ramps. Zero force data is from a TCR55 control experiment in which temperature was maintained at $34^{\circ} \mathrm{C}$. (F) Schematic indicating loss of TCR specificity at higher pMHC concentrations. (G) Mean integrated $\mathrm{Ca}^{2+}$ signals for positive cells interacting with VPLTEDALL, VPITEDSQL, VPLTEDAEL and IPLTEEAEL peptides at 1X, 7X and 27X pMHC concentrations. (H) Summarized integrated $\mathrm{Ca}^{2+}$ signals for four selected peptides under three pMHC concentrations. (I) Estimated p-value (calculated via bootstrapping, see Methods) vs. log2-transformed mean fold-change of integrated $\mathrm{Ca}^{2+}$ signals for 4 peptides at 3 different pMHC concentrations; grey area represents $p$-value $>0.013$ (Bonferroni-corrected $p$-value at a significance of 0.05 ). Error bars in $\mathbf{E}, \mathbf{G}$ and $\mathbf{H}$ indicate SEM. 
A

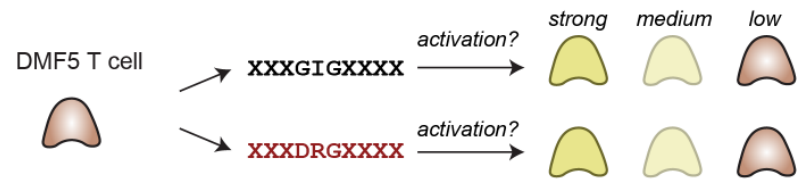

B

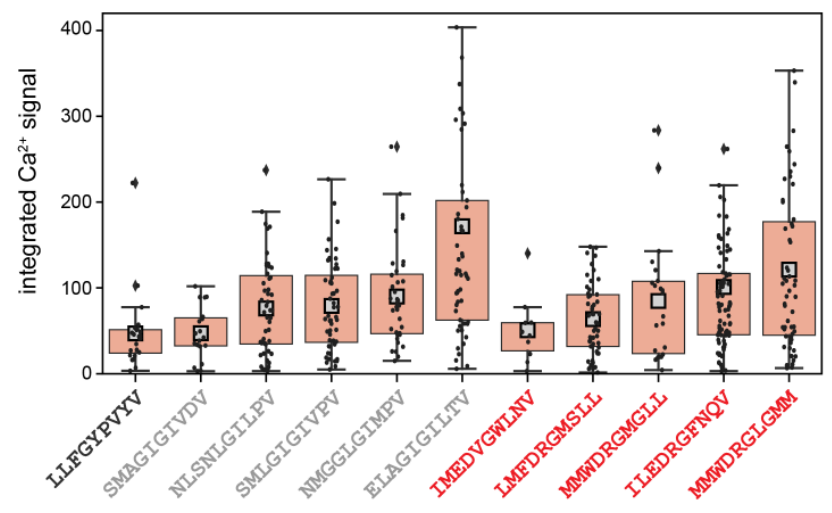

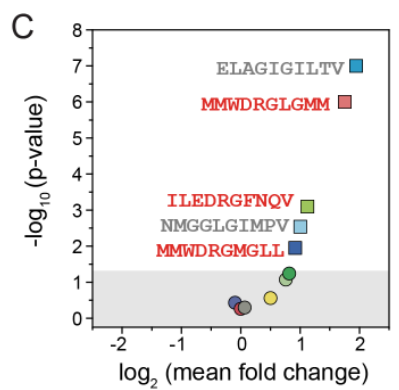

D

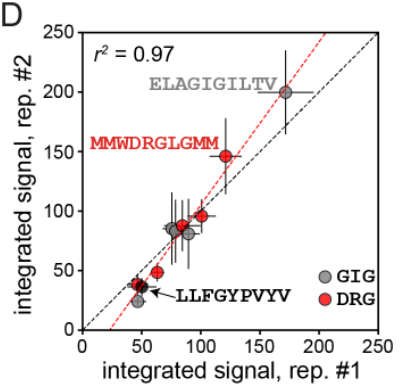

Figure 6. Activation responses for the therapeutically-relevant DMF5 TCR system interacting with 11 peptide sequences from 2 classes. (A) Schematic illustrating that DMF5 TCR shows comparable cellular reactivity to two different classes of peptide sequences (GIG and DRG, respectively) in prior co-culture assays. (B) Integrated $\mathrm{Ca}^{2+}$ signals for positive DMF5-transduced $\mathrm{T}$ cells interacting with $\mathrm{Tax}$ (LLFGYPVYV, a 'negative' control peptide identified from coculture experiments) and 10 additional peptides from the GIG (grey) and DRG (red) classes. Integrated signals for individual cells are shown as black markers; box lower and upper limits represent $25^{\text {th }}$ and $75^{\text {th }}$ percentiles, respectively; grey squares represent mean values. (C) Estimated $p$-value (calculated via bootstrapping, see Methods) vs. log2transformed mean fold change of integrated $\mathrm{Ca}^{2+}$ signals; grey area represents $p$-value $>0.05$. (D) Mean integrated $\mathrm{Ca}^{2+}$ signals for positive DMF5 cells for each peptide across 2 technical replicates. Error bars indicate SEM; dashed black line indicates the 1:1 line; red dashed line indicates linear regression. 